\title{
The response of sulfur dioxygenase to sulfide in the body wall of Urechis unincinctus
}

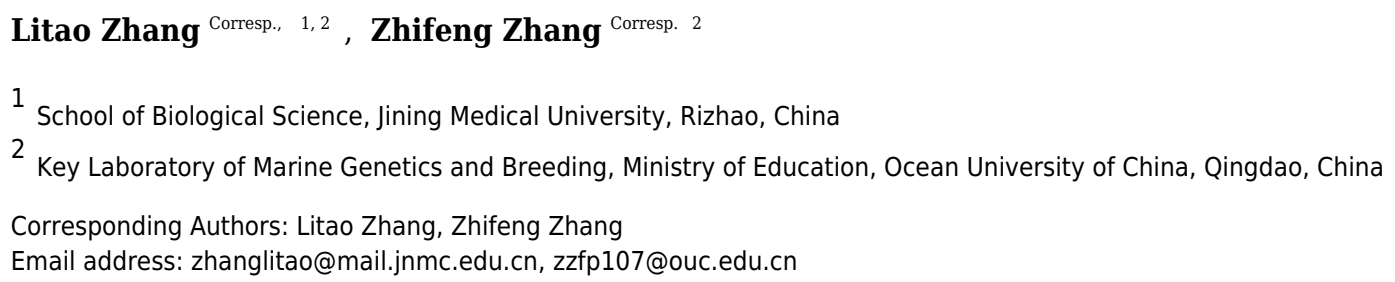

Background. In some sedimentary environments, such as costal intertidal and subtidal mudflats, sulfide levels can reach millimolar concentrations $(2-5 \mathrm{mM})$ and can be toxic to marine species. Interestingly, some organisms have evolved biochemical strategies to overcome and tolerate high sulfide conditions, such as the echiuran worm, Urechis unicinctus. Mitochondrial sulfide oxidation is important for detoxification, in which sulfur dioxygenase (SDO) plays an indispensable role. Meanwhile, the body wall of the surface of the worm is in direct contact with sulfide. In our study, we chose the body wall to explore the SDO response to sulfide. Methods. Two sulfide treatment groups 50) $\mu \mathrm{M}$ and $150 \mu \mathrm{M}$ ) and a control group (natural seawater) were used. The worms, U. unicinctus, were collected from the intertidal flat of Yantai, China, and temporarily reared in aerated seawater for three days without feeding. Finally, sixty worms with similar length and mass were evenly assigned to the three groups. The worms were sampled at 0, 6, 24, 48 and 72 $\mathrm{h}$ after initiation of sulfide exposure. The body walls were excised, frozen in liquid nitrogen and stored at $-80^{\circ} \mathrm{C}$ for RNA and protein extraction. Real-time quantitative RT-PCR, enzyme-linked immunosorbent assay and specific activity detection were used to explore the SDO response to sulfide in the body wall. Results. The body wall of $U$. unicinctus consists of a rugal epidermis, connective tissue, outer circular muscle and middle longitudinal muscle. SDO protein is mainly located in the epidermis. When exposed to 50 $\mu \mathrm{M}$ sulfide, SDO mRNA and protein contents almost remained stable, but SDO activity increased significantly after $6 \mathrm{~h}(P<0.05)$. However, in the $150 \mu \mathrm{M}$ sulfide treatment group, SDO mRNA and protein contents and activity all increased with sulfide exposure time; significant increases all began to occur at $48 \mathrm{~h}(P<0.05)$. Discussion. All the results indicated that SDO activity can be enhanced by sulfide in two regulation mechanisms: allosteric regulation, for low concentrations, and transcription regulation, which is activated with an increase in sulfide concentration. 


\section{The response of sulfur dioxygenase to sulfide in the body wall of Urechis}

2

3

4

5

6

7 Qingdao 266003, China

8 Corresponding author:

9 Litao Zhang, School of Biological Science, Jining Medical University, Rizhao 276826, China. Email:

\section{unicinctus}

Litao Zhang ${ }^{1,2}$, Zhifeng Zhang ${ }^{2}$

${ }^{1}$ School of Biological Science, Jining Medical University, Rizhao 276826, China. ${ }^{2}$ Key

Laboratory of Marine Genetics and Breeding, Ministry of Education, Ocean University of China, zhanglitao@mail.jnmc.edu.cn

Zhifeng Zhang, Key Laboratory of Marine Genetics and Breeding, Ministry of Education, Ocean University of China, Qingdao 266003, China. E-mail: zzfp107@,ouc.edu.cn

\section{Abstract}

\section{Background.}

In some sedimentary environments, such as costal intertidal and subtidal mudflats, sulfide levels can reach millimolar concentrations $(2-5 \mathrm{mM})$ and can be toxic to marine species. Interestingly, some organisms have evolved biochemical strategies to overcome and tolerate high sulfide conditions, such as the echiuran worm, Urechis unicinctus. Mitochondrial sulfide oxidation is important for detoxification, in which sulfur dioxygenase (SDO) plays an indispensable role. Meanwhile, the body wall of the surface of the worm is in direct contact with sulfide. In our study, we chose the body wall to explore the SDO response to sulfide.

\section{Methods.}

Two sulfide treatment groups $(50 \mu \mathrm{M}$ and $150 \mu \mathrm{M})$ and a control group (natural seawater) were used. The worms, U. unicinctus, were collected from the intertidal flat of Yantai, China, and temporarily reared in aerated seawater for three days without feeding. Finally, sixty worms with similar length and mass were evenly assigned to the three groups. The worms were sampled at 0 , $6,24,48$ and $72 \mathrm{~h}$ after initiation of sulfide exposure. The body walls were excised, frozen in liquid 
28 nitrogen and stored at $-80^{\circ} \mathrm{C}$ for RNA and protein extraction. Real-time quantitative RT-PCR, enzyme-linked immunosorbent assay and specific activity detection were used to explore the SDO response to sulfide in the body wall.

\section{Results.}

The body wall of $U$. unicinctus consists of a rugal epidermis, connective tissue, outer circular muscle and middle longitudinal muscle. SDO protein is mainly located in the epidermis. When exposed to $50 \mu \mathrm{M}$ sulfide, SDO mRNA and protein contents almost remained stable, but SDO activity increased significantly after $6 \mathrm{~h}(P<0.05)$. However, in the $150 \mu \mathrm{M}$ sulfide treatment group, SDO mRNA and protein contents and activity all increased with sulfide exposure time; significant increases all began to occur at $48 \mathrm{~h}(P<0.05)$.

\section{Discussion.}

All the results indicated that SDO activity can be enhanced by sulfide in two regulation mechanisms: allosteric regulation, for low concentrations, and transcription regulation, which is activated with an increase in sulfide concentration.

\section{INTRODUCTION}

Although hydrogen sulfide $\left(\mathrm{H}_{2} \mathrm{~S}\right)$ at low concentrations can act as a biological signaling molecule in many physiological processes, including regulation of vascular tone, cellular stress response, apoptosis, and inflammation (Li \& Moore, 2011; Módis et al., 2013; Kabil and Banerjee,

2014), $\mathrm{H}_{2} \mathrm{~S}$ is inherently toxic at high concentrations by reducing complex IV activity, lowering the electrochemical potential across the inner mitochondrial membrane, reducing ATP generation and inducing apoptosis (Beauchamp et al., 1984; Jiang et al., 2016). In brief, $\mathrm{H}_{2} \mathrm{~S}$ is a mitochondrial inhibitor. $\mathrm{H}_{2} \mathrm{~S}$ in solutions usually exists in forms of $\mathrm{H}_{2} \mathrm{~S}, \mathrm{HS}$-and $\mathrm{S}^{2-}$, summarized as sulfide. There are many environments rich in sulfide in nature, where abundant biological species exists (Hand \& Somero, 1983). In some sedimentary environments, such as costal intertidal and subtidal mudflats, sulfide levels can reach millimolar concentrations (Arp et al., 1992), in which animals living there have a variety of adaptations to avoid the toxicity of sulfide. Sulfide 
55 56

detoxification, especially mitochondrial sulfide detoxification, is one of the most important strategies to detoxify sulfide (Grieshaber\& Völkel, 1998). The enzyme systems including sulfide:quinine oxidoreductase (SQR), sulfur dioxygenase (SDO) and sulfur transferase (ST) take part in sulfide oxidation and convert sulfide to harmless thiosulfate, in which SDO plays an indispensable role in catalyzing persulfide oxidized to sulfite (Hildebrandt \& Grieshaber,2008; Jackson et al., 2012).

The ETHE1 (ethylmalonic encephalopathy 1) gene in humans was identified as the SDO gene, and its dysfunction can lead to a fatal autosomal recessive mitochondrial disease: ethylmalonic encephalopathy (Tiranti et al., 2009). Subsequently, the biochemical characterization of SDO and its kinetic properties were determined for humans and Arabidopsis thaliana (Kabil \& Banerjee, 2012; Holdorf et al., 2012). In rice, the ETHE1 promoter was cloned, and its activity was induced by various abiotic stresses (Kaur et al., 2014). In Acidithiobacillus caldus, two SDOs were identified; one was essential for the survival of $A$. caldus and involved energy supply, while the other might function in sulfur oxidation ( $W u$ et al., 2017). However, few studies were conducted on the SDO response to sulfide.

The echiuran worm Urechis unicinctus, which inhabits a U-shaped burrow in costal intertidal and subtidal mudflats, can tolerate sulfide and detoxify it through oxidation in mitochondria (Ma et al., 2012). The function and expression characteristics analysis of the SDO gene in U. unicinctus has been conducted before (Zhang et al., 2013, 2016). In Urechis caupo, the body was recognized as an exchange surface and as a permeation barrier, but ultrastructural studies found that the body wall does not present a significant structural barrier to permeation, so oxidation of sulfide in the body wall might play important roles (Menon and Arp, 1993). However, the responses of the enzyme involved in sulfide oxidation to sulfide in the body wall is unknown. Thus, in this study, the body wall was chosen to explore the SDO response to sulfide through RNA, protein and enzyme activity levels. Our aim is to answer the question 'how does SDO gene expression, protein concentration, and activity respond to sulfide concentrations in the body wall?' and to reveal the function of the body wall in sulfide detoxification at the molecular level. 
82 MATERIALS AND METHODS

\section{Sulfide treatment and sampling}

$84 U$. unicinctus were collected from the intertidal flat of Yantai, China. Upon arrival at the lab, 85 the worms were temporarily reared in aerated seawater $\left(18^{\circ} \mathrm{C}, \mathrm{pH} 8.0\right.$, and salinity $30 \%$ ) for three 86 days without feeding. Then, sixty worms with similar length and mass were evenly assigned to six 87 tanks containing $30 \mathrm{~L}$ of seawater and sealed with cling film. Three groups, including a control 88 group without sulfide and two sulfide treatment groups ( $50 \mu \mathrm{M}$ and $150 \mu \mathrm{M})$ were used in this 89 study. During the experiment, the sulfide concentrations were maintained by adding a sulfide stock solution (10 mM Na $2 \mathrm{~S}, \mathrm{pH} 8.0$ ) every $2 \mathrm{~h}$ as necessary, based on the determined sulfide concentration by the methylene blue method. The times for sampling were set at $0,6,24,48$ and

$9272 \mathrm{~h}$ after initiation of sulfide exposure. The body walls were excised, frozen in liquid nitrogen 93 and stored at $-80^{\circ} \mathrm{C}$ for RNA and protein extraction.

\section{RNA isolation and qRT-PCR}

Total RNA from the body wall of $U$. unicinctus was extracted by the TRIzol reagent (Invitrogen, CA, USA) according to the manufacturer's instructions. The quality of the RNA samples was assessed by a NanoDrop microvolume spectrophotometer (Thermo Scientific, CA, USA) and by electrophoresis using a 1.2\% agarose gel. The cDNA templates were obtained using a PrimeScript RT reagent Kit with gDNA Eraser (Takara, Otsu, Japan). The expression pattern of SDO was determined by qRT-PCR and normalized with the reference gene $\beta$-actin (GenBank accession no. GU592178.1). All the primers used in the study are listed in Table 1. qRT-PCR was performed in a 7500 Real-Time PCR System (ABI, CA, USA) with a $20 \mu \mathrm{L}$ reaction volume containing $2 \mu \mathrm{L}$ of template cDNA, $0.8 \mu \mathrm{L}$ of each primer $(10 \mu \mathrm{M}), 0.4 \mu \mathrm{L}$ of $50 \times$ ROX Reference Dye II, $10 \mu \mathrm{L}$ of $2 \times$ SYBR Premix Ex Taq (Takara, Otsu, Japan) and $6 \mu$ of PCR-grade water. Each reaction was performed in quadruplicates. The relative expression levels of SDO were analyzed according to the $2^{-\Delta \Delta \mathrm{CT}}$ method.

\section{Antibody preparation and ELISA}

108 The SDO recombinant protein of $U$. unicinctus has previously been successfully obtained by 
109 the PET Express System (Zhang et al., 2013). SDO protein was expressed in the form of inclusion

110 bodies and therefore dissolved in $8 \mathrm{M}$ urea and purified by Ni-NTA affinity chromatography

111 (Novagen, Darmstadt, Germany). The purified SDO protein was used to produce rabbit-anti- $U$.

112 unicinctus polyclonal antibody by Sangon Biotechnology (Shanghai, China). The specificity of the

113 SDO antibody was validated by western blot and deemed appropriate for ELISA to determine SDO

114 protein contents. The protein from different tissues were extracted using a Tissue Protein

115 Extraction Kit (CWBIO, China). Tissue $(0.1 \mathrm{~g})$ was placed into $1 \mathrm{ml}$ of tissue protein extraction

116 reagent (50mM Tris- $\mathrm{Cl}, 150 \mathrm{mM} \mathrm{NaCl}, 1 \% \mathrm{NP} 40$ and $0.5 \%$ sodium deoxycholate) with $10 \mu \mathrm{L}$ of

117 the protease inhibitor cocktail, and then the sample was homogenized and placed on ice for 20

118 min. After centrifugation at $12000 \mathrm{rpm}$ for $30 \mathrm{~min}$, tissue protein was obtained, and its

119 concentration was determined by the Coomassie brilliant blue method. The indirect competitive

120 ELISA method was established previously, and the SDO contents in the body wall were calculated

121 as described previously (Zhang et al., 2016). Each reaction was performed in quintuplicate.

\section{Immunohistochemistry}

123 To assess the SDO location in the body wall, paraffin sections $(7 \mu \mathrm{m})$ were first cut using a

124 Histostart 820 Rotary microtome (Reichert, Depew, NY, USA). Then, the sections were dewaxed

125 in xylene and gradient alcohol. After that, antigen retrieval for the sections was conducted with

126 the procedure in $3 \% \mathrm{H}_{2} \mathrm{O}_{2}$ at room temperature for $15 \mathrm{~min}$ and in EDTA $\left(0.05 \mathrm{M} \mathrm{pH} \mathrm{8.0)}\right.$ at $85^{\circ} \mathrm{C}$

127 for $1 \mathrm{~h}$. Nonspecific protein binding was blocked with 3\% bovine serum albumin (BSA) for 30

$128 \mathrm{~min}$. The sections were incubated in rabbit anti-SDO antibody (diluted 1:500) or preimmune serum,

129 as the negative control, for $1 \mathrm{~h}$. Then, incubation was followed by washing the tissue section

130 followed by a 30 min incubation with HRP-labeled goat anti-rabbit IgG (diluted 1:1000)

131 (Sangon). The staining was completed by the use of an HRP Color Development Kit (Solarbio,

132 Shanghai, China). Next, sections were counterstained with hematoxylin, dehydrated and

133 mounted in Pertex. A Nikon E80i microscope (Nikon, Tokyo, Japan) was used to observe and 134 photograph the sections.

\section{Analysis of SDO specific activity}


136 Total SDO specific activity was determined by the improved Kabil and Banerjee method 137 (2012). The reaction mixture $(2 \mathrm{ml})$ contained $1 \mathrm{ml}$ of potassium phosphate buffer $(0.2 \mathrm{M}, \mathrm{pH} 7.4)$, $138200 \mu \mathrm{L}$ of $10 \mathrm{mM}$ reduced glutathione, $30 \mu \mathrm{L}$ of a saturated acetonic sulfur solution and $750 \mu \mathrm{L}$ 139 of sterile water. Twenty microliters of the total organ protein were added to initiate the reaction, 140 and the Oxytherm oxygen measurement system (Hansatech, Pentney, UK) was used to record the 141 rate of $\mathrm{O}_{2}$ consumption at $25^{\circ} \mathrm{C}$. The $\mathrm{O}_{2}$ consumption rate per mg total organ protein $(1 \mu \mathrm{mol}$ of

$142 \mathrm{O}_{2} \min ^{-1} \mathrm{mg}$ total protein ${ }^{-1}$ ) was used to represent the SDO specific activity from the total protein 143 (U mg total protein $\left.{ }^{-1}\right)$.

144 Statistical analysis

145 All parametric data are expressed as the mean \pm standard error (SE). Statistical comparisons 146 among means were tested by one-way ANOVA (analysis of variance), and a value of $P<0.05$ was 147 considered significant (computed by SPSS version 18.0 for Windows).

\section{RESULTS}

\section{SDO distribution in the body wall}

150 The structure of the body wall, as observed by a light microscope, is shown in Fig. 1A. The 151 surface of the body wall is epidermis with abundant rugae; subjacent to the epidermis is a thin 152 layer of connective tissue, and below it are two distinct muscle layers: an outer circular muscle 153 and a middle longitudinal muscle. The immunohistochemistry results showed that SDO protein 154 was mainly expressed in epithelial tissue (Fig. 1B). Moreover, the negative control had no positive 155 signals (Fig. 1C), which provides assurance that the results are accurate.

\section{Changes in SDO mRNA levels after sulfide exposure}

157 The temporal expression levels of SDO mRNA in the different treatment groups were examined 158 at $0,6,24,48$ and $72 \mathrm{~h}$ by qRT-PCR (Fig. 2). In the $50 \mu \mathrm{M}$ sulfide treatment group (Fig. 2), no

159 significant changes were observed during different sulfide exposure times. However, in the 150 $160 \mu \mathrm{M}$ sulfide treatment group (Fig. 2), the expression level of SDO mRNA was upregulated at $48 \mathrm{~h}$ 161 (1.885-fold, $P<0.05)$ and $72 \mathrm{~h}(2.183$-fold, $P<0.05)$. Furthermore, there was no obvious change 162 in the control group during the whole experimental process. 
163 3.3. Expression pattern of SDO protein after sulfide exposure

164 The SDO protein contents in different treatment groups were determined by ELISA at 0, 6, 24, 16548 and $72 \mathrm{~h}$ (Fig. 3). The SDO contents increased with the time of sulfide exposure, but no 166 significant difference occurred during the experiment in the $50 \mu \mathrm{M}$ sulfide treatment group (Fig.

167 3). In the $150 \mu \mathrm{M}$ sulfide treatment group (Fig. 3), a distinct time-dependent elevation of the SDO 168 protein level was observed compared with the SDO contents at $0 \mathrm{~h}(1.103 \pm 0.085 \mathrm{ng} \mu \mathrm{g}$ total 169 protein $\left.^{-1}\right)$, and a significant increase in the SDO level $(P<0.05)$ was observed at $48 \mathrm{~h}(1.723 \pm$ $1700.076 \mathrm{ng} \mu \mathrm{g}$ total protein $\left.{ }^{-1}\right)$ and at $72 \mathrm{~h}\left(2.165 \pm 0.079 \mathrm{ng} \mu \mathrm{g}\right.$ total protein $\left.{ }^{-1}\right)$ after sulfide exposure.

171 Moreover, no obvious change in the control group was observed during the whole experiment

\section{3.4. SDO activity responses to sulfide}

173 The T-SDO SA (total SDO specific activity from total protein) was detected using a Clark 174 oxygen electrode at 0, 6, 24, 48 and $72 \mathrm{~h}$ in different groups (Fig. 4). No significant differences in 175 T-SDO SA $(p>0.05)$ were observed at the various detected times for the control group (Fig. 4). 176 The T-SDO SA was elevated gradually with the delay in sulfide exposure time in both the $50 \mu \mathrm{M}$ 177 and $150 \mu \mathrm{M}$ sulfide treatment groups; in $50 \mu \mathrm{M}$ sulfide treatment group, the significant increase 178 in T-SDO SA $(p<0.05)$ occurred at $6 \mathrm{~h}$, reaching $0.130 \pm 0.012 \mathrm{U} \mathrm{mg} \mathrm{total} \mathrm{protein}^{-1}$, and then 179 became stable, while the T-SDO SA was elevated significantly $(p<0.05)$ at $48 \mathrm{~h}(0.159 \pm 0.002 \mathrm{U}$ $180 \mathrm{mg}$ total protein ${ }^{-1}$ ) with the presence of a significant increase at $72 \mathrm{~h}$ (Fig. 4).

\section{Discussion}

182 The body wall, which is located at the surface of $U$. unicinctus, is in direct contact with sulfide 183 in the environment. Therefore, it has its own special histological adaption for the protection of 184 internal organs. HE staining of histological sections (Fig. 1A) revealed that the epidermis is in the

185 form of rugae. Therefore, the surface area for oxygen uptake increases to ensure the oxygen supply 186 in a sulfide-rich environment. The muscle in the body wall is thick and sinewy (Fig. 1A), which is

187 helpful for the peristaltic movements of the body wall to obtain oxygen and feeding currents in the 188 burrow. A similar structure has also been illustrated in U. caupo (Menon \& Arp, 1993). It has been 189 reported that there are no tight junctions in invertebrate epidermis except for tunicates (Lillywhite 
190 \& Maderson, 1988). In U. unicinctus, no tight junctions were also observed. Thus, it was

191 concluded that sulfide can permeate the body wall of U. unicinctus, and therefore, the sulfide

192 should be detoxified by the organism itself. Sulfide oxidation in mitochondria is the most important

193 strategy for sulfide detoxification.

194 In mitochondrial sulfide oxidation, SDO can oxidize persulfide to sulfite in the presence of

195 oxygen, which is indispensable. The persulfide is produced by SQR with the substrates - sulfide

196 and GSH (Hildebrandt \& Grieshaber, 2008) or by ST with the substrates thiosulfate and GSH

197 (Jackson et al., 2012). In our study, we found that SDO protein was mainly located in the epidermis

198 of the body wall (Fig. 1B). In addition to increasing the respiratory surface area for gas exchange,

199 the rugae in the epidermis of the body wall can also increase permeable surface area for sulfide to 200 enter the body. Therefore, the location of SDO is important for counteracting sulfide via oxidation.

201 Furthermore, the presence of rugae can also increase SDO contents by extending the area of the 202 epidermis and is also helpful for uptake of the SDO substrate oxygen.

203 The SDO response to sulfide in the midgut and hindgut has been reported; the T-SDO SA in the 204 midgut is kept stable by elevating the level of SDO protein while SDO in the hindgut displays a 205 similar response pattern in both high and low concentrations of sulfide (Zhang et al., 2016). From 206 the results of SDO response to sulfide in the gut, it is discovered that the specific enzyme activity 207 of SDO protein is down-regulated by allosteric regulation and the T-SDO SA is maintained even 208 elevated by the increasing the SDO contents by transcription regulation. However, the SDO 209 response to sulfide in the body wall is regulated by two different mechanisms to enhance the 210 enzyme activity according to the sulfide concentration. At the high concentrations of sulfide (150 $211 \mu \mathrm{M}$ ), the SDO activity (Fig. 4) increased with the increase in SDO protein contents (Fig. 3); 212 furthermore, SDO protein expression patterns (Fig. 3) were consistent with mRNA level changes 213 (Fig. 2). All of the results indicated that sulfide enhances SDO activity by promoting SDO mRNA 214 transcription to elevate the SDO protein. However, in low concentrations of sulfide $(50 \mu \mathrm{M})$, the 215 mRNA levels and protein contents of SDO were both almost constant (Fig. 2 and Fig. 3), but the 216 SDO activity was elevated significantly (Fig. 4), which indicated that sulfide might elevate SDO 
217 activity by allosteric regulation. GSH might play an important role in the allosteric regulation of

218 SDO. Zhang et al. have proved that GSH can bind to the SDO protein (Zhang et al., 2013), and

219 SDO activity in humans can be elevated by GSH (Kabil \& Banerjee, 2012). From the above, when

220 the concentration of sulfide is low, the sulfide might induce GSH binding to SDO to enhance the

221 activity of sulfide oxidation. The response is quick, and the significant increase in SDO activity

222 occurred at $6 \mathrm{~h}$ (Fig. 4). As the concentration of sulfide increases, GSH can be consumed to

223 eliminate the reactive oxygen species induced by sulfide (Pompella et al., 2003) or by SQR

224 catalyzing sulfide into persulfide (Theissen \& Martin, 2012). Therefore, to enhance SDO activity,

225 SDO protein contents were elevated after transcription was promoted. This response needs more

226 time and is slow. It took approximately $48 \mathrm{~h}$ for the significant increase in SDO activity to occur.

\section{Conclusions}

228 In summary, the epidermis of body wall in U. unicinctus is rugal, where the SDO protein located, which is important for counteracting sulfide via oxidation. When responding to sulfide, SDO activity can be enhanced for sulfide detoxification. The mRNA and protein expression analyses

231 indicated that there are two regulation mechanisms for the increase of SDO activity: allosteric

232 regulation at low sulfide concentrations and transcription regulation at high sulfide concentrations.

\section{References}

234 Arp AJ, Hansen BM, Julian D. 1992. The burrow environment and coelomic fluid characteristics of the echiuran worm Urechis caupo from three northern California population sites. Marine Biology 113:613-623.

Beauchamp RO, Bus JS, Popp JA, Boreiko CJ, Andjelkovich DA. 1984. A critical review of the literature on hydrogen sulfide toxicity. Critical Reviews in Toxicology 13:25-97.

Grieshaber MK, Völkel S. 1998. Animal adaptations for tolerance and exploitation of poisonous sulfide. Annual Review of Physiology 60:33-53.

241 Hand SC, Somero G N. 1983. Energy Metabolism pathways of hydrothermal vent animals: adaptations to a food-rich and sulfide-rich deep-sea environment. Biological Bulletin, 165(1):167-181. 
244 Hildebrandt TM, Grieshaber MK. 2008. Three enzymatic activities catalyze the oxidation of 245 sulfide to thiosulfate in mammalian and invertebrate mitochondria. FEBS Journal 275:33523361.

Holdorf MM, Owen HA, Lieber SR, Yuan L, Adams N, Dabney-Smith C, Makaroff CA. 2012. Arabidopsis ETHE1 encodes a sulfur dioxygenase that is essential for embryo and endosperm development. Plant Physiology 160:226-236.

Jackson MR, Melideo SL, Jorns MS. 2012. Human sulfide:quinone oxidoreductase catalyzes the first step in hydrogen sulfide metabolism and produces a sulfane sulfur metabolite. Biochemistry 51:6804-6815.

Jiang J, Chan A, Ali S, Saha A, Haushalter KJ, Lam WL, Glasheen M, Parker J,Brenner M, Mahon SB, Patel HH, Ambasudhan R, Lipton SA, Pilz RB, Boss GR. 2016. Hydrogen Sulfide-Mechanisms of Toxicity and Development of an Antidote. Scientific Reports 6:20831.

Julian D, Arp AJ. 1992. Sulfide permeability in the marine invertebrate Urechis caupo. Journal of Comparative Physiology B 162:59-67.

Kabil O, Banerjee R. 2012. Characterization of patient mutations in human persulfide dioxygenase (ETHE1) involved in $\mathrm{H}_{2} \mathrm{~S}$ catabolism. Journal of Biological Chemistry 287:44561-44567.

Kabil O, Banerjee R. 2014. Enzymology of $\mathrm{H}_{2} \mathrm{~S}$ biogenesis, decay and signaling. Antioxidants \& Redox Signaling 20:770-782.

Kaur C, Mustafiz A, Sarkar AK, Ariyadasa TU, Singlapareek SL, Sopory SK. 2014. Expression of abiotic stress inducible ETHE1-like protein from rice is higher in roots and is regulated by calcium. Physiologia Plantarum 152:1-16.

Li L, Rose P, Moore PK. 2011. Hydrogen Sulfide and Cell Signaling. Annual Review of Pharmacology and Toxicology 51:169-187.

Lillywhite H, Maderson P. 1988. The Structure and Permeability of Integument. Integrative \& Comparative Biology 28:945-962. 
271

272

273

274

275

276

277

278

279

280

281

282

283

284

285

286

287

288

289

290

291

292

293

294

295

296

297

Ma YB, Zhang ZF, Shao MY, Kang KH, Tan Z, Li JL. 2011. Sulfide:quinone oxidoreductase from echiuran worm Urechis unicinctus. Marine Biotechnology 13:93-107.

Ma YB, Zhang ZF, Shao MY, Kang KH, Shi XL, Dong YP, Li JL. 2012a. Response of sulfide:qinone oxidoreductase to sulfide exposure in the echiuran worm Urechis unicinctus. Marine Biotechnology 14:245-251.

Ma YB, Zhang ZF, Shao MY, Kang KH, Zhang LT, Shi XL, Dong YP. 2012b. Function of the anal sacs and mid-gut in mitochondrial sulphide metabolism in the echiuran worm Urechis unicinctus. Marine Biology Research 8:1026-1031.

Menon J, Arp A. 1993. The Integument of the marine echiuran worm Urechis caupo. Biological Bulllletin 185:440-454.

Módis K, Wolanska K, Vozdek R. 2013. Hydrogen sulfide in cell signaling, signal transduction, cellular bioenergetics and physiology in C. elegans. G eneral Physiology \& Biophysics 32: $1-22$.

Pompella A, Visvikis A, Paolicchi A, Tata VD, Casini AF. 2003. The changing faces of glutathione, a cellular protagonist. Biochemical Pharmacology 66:1499-1503.

Theissen U, Martin W. 2008. Sulfide: quinone oxidoreductase ( $S Q R)$ from the lugworm Arenicola marina shows cyanide-and thioredoxin-dependent activity. FEBS Journal 275: $1131-1139$.

Tiranti V, Viscomi C., Hildebrandt T, Di Meo I, Mineri R, Tiveron C, Levitt MD, Prelle A, Fagiolari G, Rimoldi M, Zeviani M. 2009. Loss of ETHE1, a mitochondrial dioxygenase, causes fatal sulfide toxicity in ethylmalonic encephalopathy. Nature Medicine 15:200-205.

Wu W, Pang X, Lin J, Liu X, Wang R, Chen L. 2017. Discovery of a new subgroup of sulfur dioxygenases and characterization of sulfur dioxygenases in the sulfur metabolic network of Acidithiobacillus caldus. Plos One 12:e183668.

Zhang L, Liu X, Liu J, Zhang Z. 2013. Characteristics and function of sulfur dioxygenase in echiuran worm Urechis unicinctus. Plos One 8:e81885.

Zhang L, Liu X, Qin Z, Liu J, Zhang Z. 2016. Expression characteristics of sulfur dioxygenase 
298 and its function adaption to sulfide in echiuran worm Urechis unicinctus. Gene 593:334-341. 
Table $\mathbf{1}$ (on next page)

Sequences of designed primers used in this study. 


\begin{tabular}{ccc}
\hline Primer & Sequence & Product Length \\
\cline { 1 - 2 } SDO-F & 5'-ACAGGGATGTTCGTATCGTCAA-3' & \multirow{2}{*}{$165 \mathrm{bp}$} \\
\cline { 1 - 2 } SDO-R & 5'-ATTCGGCAATCACACTCTTACG-3' & \\
\cline { 1 - 2 } $\boldsymbol{\beta}$-actin-F & 5'-CACACTGTCCCCATCTACGAGG-3' & \multirow{2}{*}{$153 \mathrm{bp}$}
\end{tabular}

1 
Figure 1

SDO protein distribution in the body wall of $U$. unicinctus

A. Hematoxylin-eosin (H\&E) stain; B. Positive results of immunohistochemistry, insets, magnification of the box in the same picture; $\mathrm{C}$. Negative control. The scale bars in the insets of images are $100 \mathrm{~nm}$. Abbreviation: $\mathrm{CT}$, connective tissue; $\mathrm{E}$, epithelial tissue; $\mathrm{ML}$, middle longitudinal muscle; OC, outer circular muscle; $\mathrm{R}$, rugae.

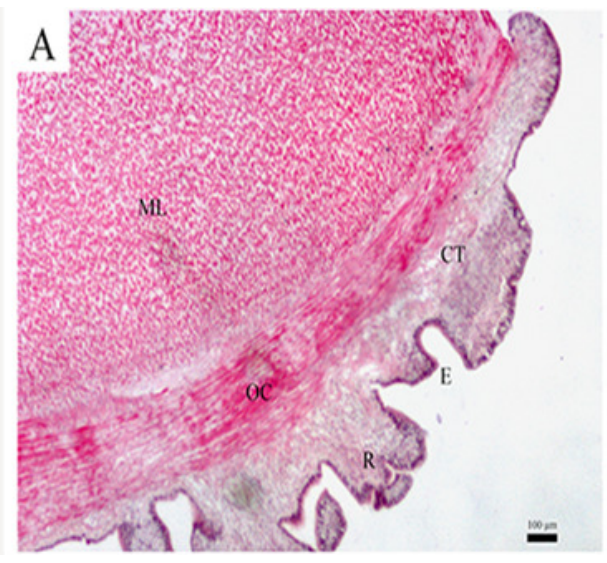

B

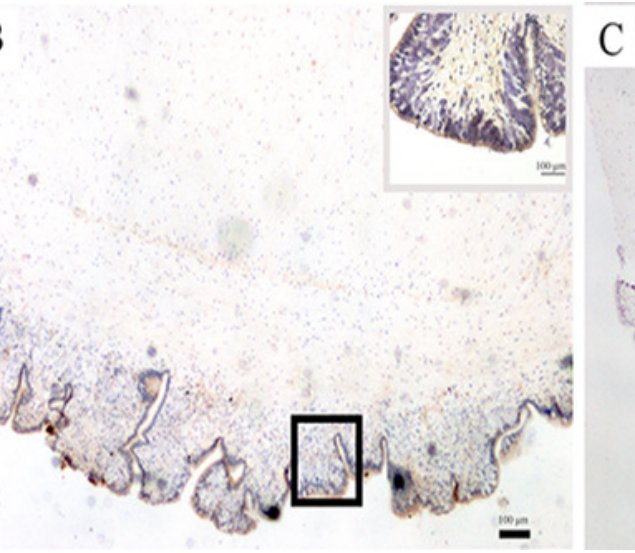


Figure 2

Relative expression levels of SDO in different sulfide treatment groups.

The data are mean \pm S.E. for each group $(n=4)$. Differing letters indicate significant differences among different groups $(P<0.05)$; identical letters indicate no significant difference $(P>0.05)$.

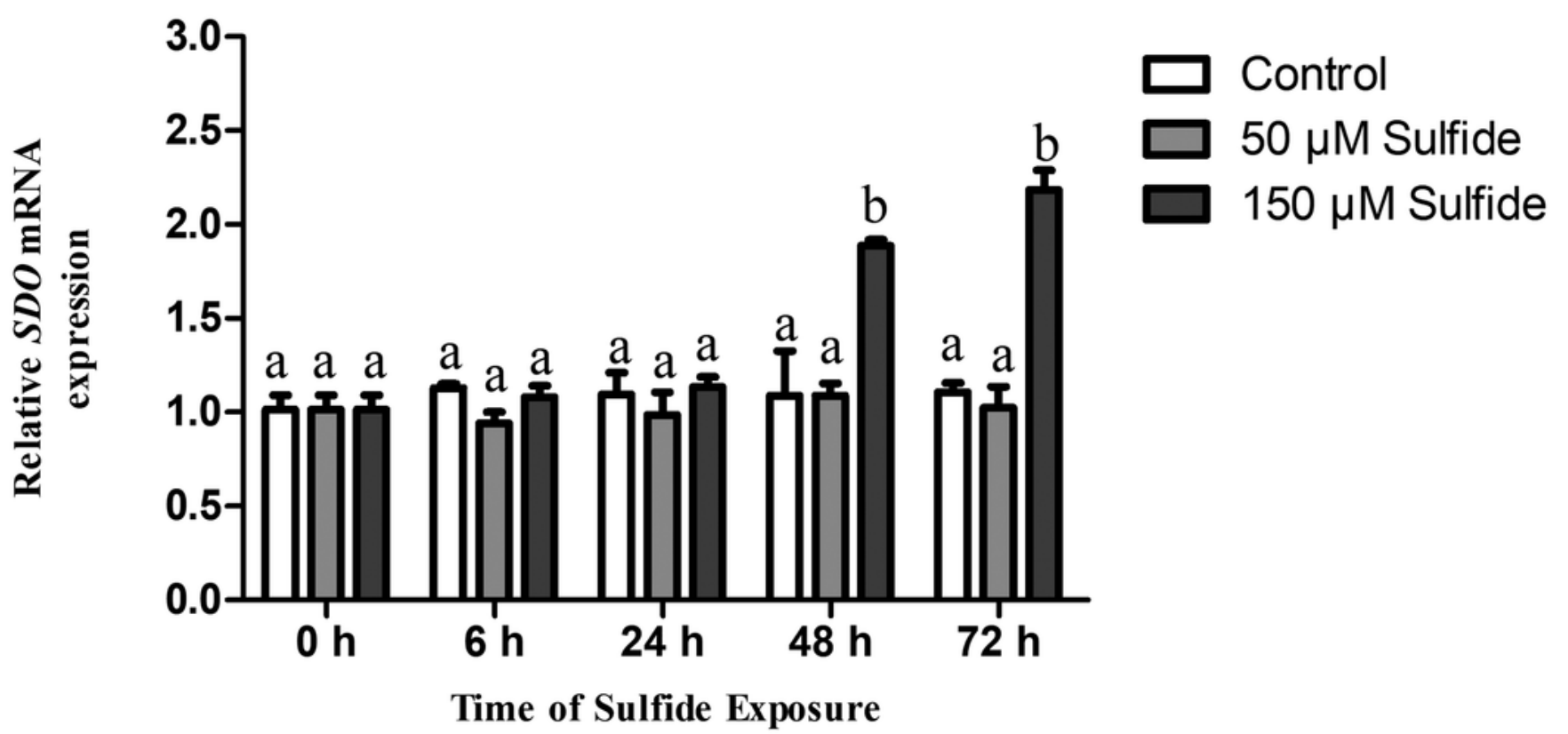


Figure 3

SDO protein contents expression pattern in different sulfide treatment groups.

The data are mean \pm S.E. for each group $(n=4)$. Differing letters indicate significant differences among different groups $(P<0.05)$; identical letters indicate no significant difference $(P>0.05)$.

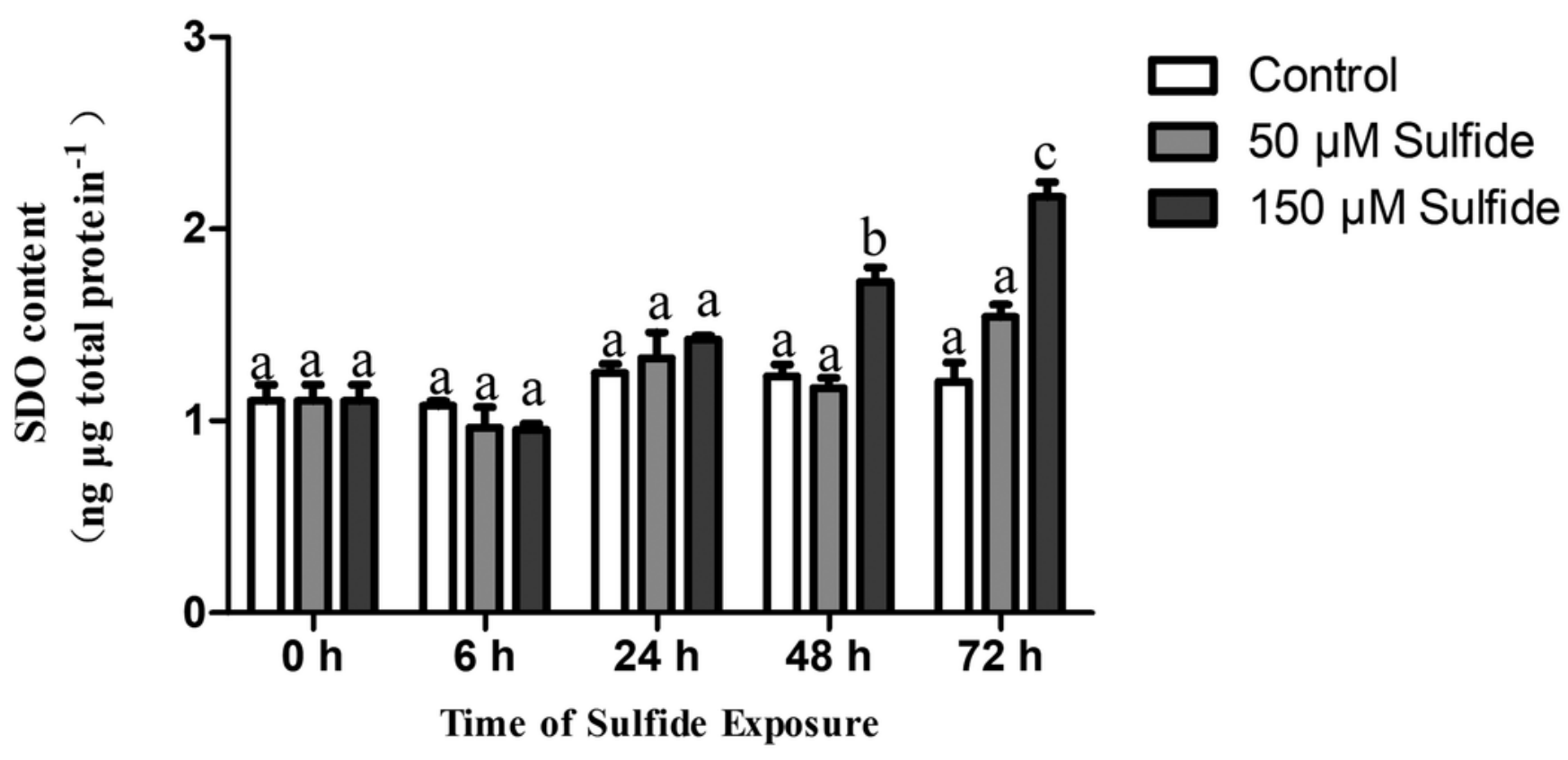


Figure 4

SDO activity response to sulfide in different groups.

The data are mean \pm S.E. for each group $(n=6)$. Differing letters indicate significant differences among different groups $(P<0.05)$; identical letters indicate no significant difference $(P>0.05)$.

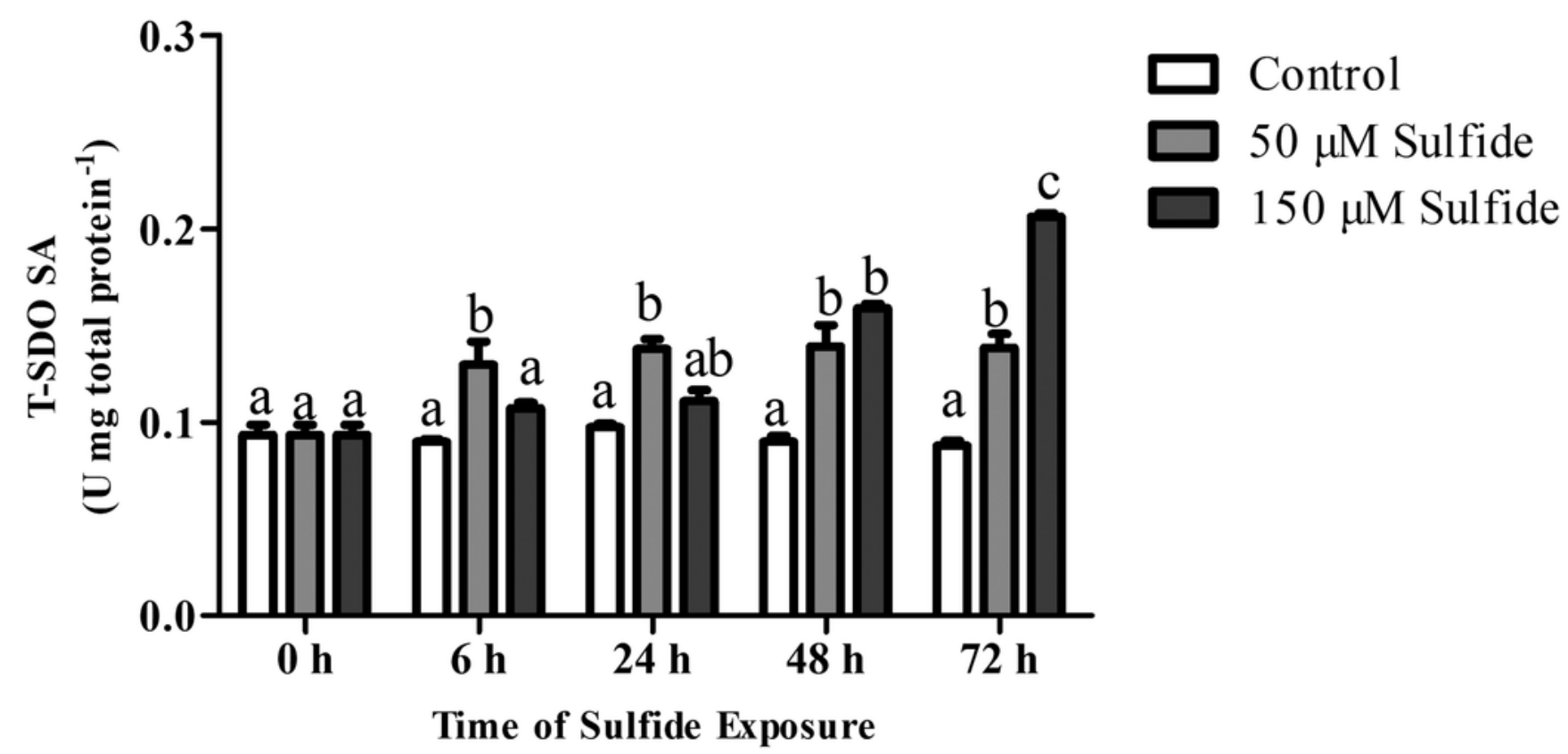

